\title{
A cognitive-behavioural program for adolescents with chronic pain - a pilot study
}

\author{
Vivian P.B.M. Merlijn ${ }^{\mathrm{a}, \mathrm{b}, *}$, Joke A.M. Hunfeld ${ }^{\mathrm{a}}$, Johannes C. van der Wouden ${ }^{\mathrm{b}}$, \\ Alice A.J.M. Hazebroek-Kampschreur ${ }^{\mathrm{c}}$, Lisette W.A. van Suijlekom-Smit ${ }^{\mathrm{d}}$, \\ Bart W. Koes ${ }^{\mathrm{b}}$, Jan Passchier ${ }^{\mathrm{a}}$ \\ ${ }^{a}$ Erasmus MC Rotterdam, Department of Medical Psychology and Psychotherapy, Rotterdam, The Netherlands \\ ${ }^{\mathrm{b}}$ Erasmus MC Rotterdam, Department of General Practice, Rotterdam, The Netherlands \\ ${ }^{\mathrm{c}}$ Municipal Health Service Rotterdam, Rotterdam, The Netherlands \\ ${ }^{\mathrm{d}}$ Erasmus MC Rotterdam, Sophia Children's Hospital, Department of Paediatrics, Rotterdam, The Netherlands
}

Received 2 January 2004; received in revised form 11 October 2004; accepted 14 October 2004

\begin{abstract}
The purpose of this pilot study is to evaluate the feasibility of a cognitive-behavioural training program for adolescents with chronic pain irrespective of pain localisation. A secondary aim was to give an impression of the effect of the program on pain and quality of life. Eight adolescents (14-18 years) with chronic non-organic pain recruited from the general population (and their parents) participated in this pilot study. The intervention included five group meetings alternated with four telephone contacts (during the self-management weeks) over a period of 9 weeks. The training aimed to change pain behaviour through pain education, relaxation strategies, problem-solving techniques, assertiveness training, cognitive restructuring and by stimulating the adolescent's physical activity level. The training further addresses the social context of pain by inviting parents to attend two meetings for the parents only, and by asking the adolescents to bring a peer to one of the meetings. Adolescents and their parents were positive about the program. Adolescents felt they were more in control of their pain and parents valued the support they experienced in helping their children to master the pain. The training was considered to be feasible in daily life. Further, the preliminary data showed an effect on pain and quality of life in the expected direction. The results underline the need for a definitive study with a larger sample size and a random controlled design.
\end{abstract}

(C) 2004 Elsevier Ireland Ltd. All rights reserved.

Keywords: Chronic pain; Adolescents; Cognitive-behavioural intervention; Pilot study

\section{Introduction}

Chronic pain is often associated with complex social and psychological problems. It has been shown to lead to considerable medical consumption [1], school absenteeism and nuisance in the adolescents' life [2]. As a consequence of the pain adolescents with chronic pain evaluate their quality of life as being less satisfactory than their healthy peers [3]. There is a growing interest in improving the quality of life of pain patients, but pain relief remains the main goal of treatment [4]. A recent systematic review

\footnotetext{
* Corresponding author. Tel.: +31 1040887 07; fax: +31 104089420 .

E-mail address: v.merlijn@erasmusmc.nl (Vivian P.B.M. Merlijn).
}

showed that psychological treatments are effective in reducing the severity and frequency of chronic headache in children and adolescents [5]. However, few psychological treatments for adolescents with chronic pain other than headache have been evaluated in a randomised controlled study design. Significant reductions in pain and improvements in functioning were achieved in children and adolescents with recurrent abdominal pain [6] and complex regional pain syndromes [7]. Although psychological treatments based on the principle of cognitive behavioural therapy are effective for adolescents with chronic pain, until now they have been limited to a single pain complaint. A program suitable for a wider spectrum of chronic pain sufferers might enhance its utility. 
To facilitate the applicability of clinically-based treatments, several psychological interventions have a selfadministered format [8]. In the field of chronic pain in children and adolescents, self-management programs have been shown to be as effective as psychological treatment guided by a therapist, but less expensive [9-11]. On the other hand, a therapy group has been reported to be more appealing to adolescents [12]. Groups give adolescents the opportunity for modelling, problem solving, helping others and relating to peers who share similar circumstances, all of which are more difficult to arrange through individual therapy or self-administered programs $[13,14]$. A combination of both forms, i.e. self-management alternated with group sessions, enables to benefit from the positive aspects of both.

Most psychological interventions involve the chronic pain sufferer only, whereas the importance of the social context of chronic pain is increasingly emphasized [15]. Although only a few treatments involve the parents of children and adolescents with chronic pain, the results are promising. For example, parents rated treatments in which they were involved as more satisfying and effective $[6,16]$. These experiences were supported by clinical improvements in pain severity and frequency $[6,17]$. Maternal caregiving strategies have been shown to be significant and independent predictors of clinical improvement in pain behaviour [17]. Parent-mediated guidelines for pain behaviour management may therefore be considered as an important addition to management programs for chronic pain in children and adolescents. With the growing influence of peers in adolescence, the social network is no longer limited to the adolescent's family; this may implicate the need for the involvement of peers in psychological interventions.

We have developed a cognitive-behavioural program for adolescents with chronic pain at different localisations based on a model of the quality of life of adolescents with nonspecific chronic pain. The model is shown in Fig. 1.

This model was tested with regression analysis in previous studies of our group. These studies showed that adolescents (12-18 years) with chronic pain from the general population had higher levels of neuroticism, greater

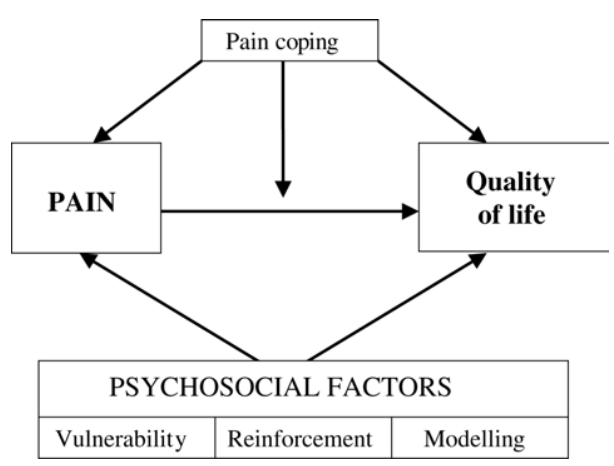

Fig. 1. Model of quality of life in adolescents with chronic pain. fear of failure and were less socially accepted than a control group [3]. Further, the chronic pain group experienced less attention for their pain behaviour by both parents and peers, and reported more pain models in their environment. A regression analysis on the amount of pain in the chronic pain group sustained the positive relationships of vulnerability, (less) pain reinforcement, pain models and emotion focused avoidance coping (i.e. somatization) with pain [3]. Additional multiple hierarchical regression analyses revealed that the psychosocial factors (vulnerability, reinforcement and modeling) and pain-coping strategies also accounted for a significant variance in the adolescent's quality of life, even when controlling for pain characteristics [18]. Pain intensity and vulnerability contributed significantly and uniquely to the variance of most quality of life domains. In addition, the negative relationship between pain and quality of life is strengthened by the level of emotion-focused avoidance coping: for adolescents who report more emotion-focused avoidance coping, a higher level of pain is associated with lower level of psychological functioning. These results suggest that intervention programs directed at reducing the impact of pain on quality of life in adolescents with chronic pain should also include techniques aiming at coping skills of the adolescents emotion-focused avoidance, at reducing their vulnerability and at increasing the understanding of the environment about psychological aspects of chronic pain. These results are used as a guide for our cognitivebehavioural program. The present pilot study evaluates the feasibility of this program. A secondary aim was to give an impression on its potential beneficial effect on pain and quality of life.

\section{Methods}

\subsection{Subjects}

Adolescents were selected from a previous general population sample [3] of adolescents with chronic pain to obtain a sample of 8 participants, being the maximum group size for the training. From the 86 eligible adolescents, we randomly selected 8 adolescents. If a selected adolescent refused participation we randomly selected another adolescent. Adolescents who were included reported recurrent or continuous chronic pain (without documented physiological etiology) that had persisted for at least 3 months once a week with an intensity of $30 \mathrm{~mm}$ or more (measured on a VAS) and resulted in pain-associated disability at baseline [3].

\subsection{Procedure}

The Medical Ethics Committee of the Erasmus Academic Medical Center, Rotterdam approved the study. Adolescents and their parents were telephoned and invited to participate in a pilot study of our cognitive-behavioural program. We explained that the program was developed based on the 
results of our earlier study in which they had participated [3], and that the main goals of the pilot study were to evaluate the feasibility of the program and to explore its effects.

The outcome variables pain and quality of life were assessed two weeks prior to the initiation of the training at pretreatment $\left(T_{0}\right)$, directly after the 9 weeks of intervention at post-treatment $\left(T_{1}\right)$, and 1 year after ending the intervention at follow-up $\left(T_{2}\right)$. Adolescents and their parents anonymously completed the evaluation form at post-treatment $\left(T_{1}\right)$.

\subsection{Cognitive-behavioural program}

The intervention consisted of a combination of five group meetings and four telephone contacts, during a period of 9 weeks. The meetings were held at the Erasmus MC from 5.00 p.m. until 6.30 p.m. The group meetings were alternated with self-management weeks (plus telephone contacts) and supported with a training and exercise book. Parents were invited to attend two meetings dedicated to the parents only; one at the beginning and one at the end of the intervention period. In session five the adolescents were asked to bring a peer to the meeting.

\subsubsection{Rationale of the program}

The program is related to the psychosocial factors of our model (Fig. 1) in the following way. Our program focuses mainly on reducing the vulnerability of the adolescents by means of cognitive techniques (psycho-education, rational emotive therapy), behavioural techniques (respondent conditioning: relaxation exercises) and social learning techniques (modeling healthy behaviour by others in case of pain behaviour, modeling resilience in case of fear of failure or diminished social assertiveness). Reinforcement was addressed by means of behavioural techniques (operant conditioning: positive reinforcement of healthy behaviour and extinction of pain behaviour). Social learning techniques were used to explain the mechanism of modeling. Raising consciousness was achieved by asking parents to monitor their own pain behaviour in relation to the pain behaviour their child.

The techniques used in our program are related to two major psychological theories (i.e. the behavioural and social learning theory and cognitive theories). The program emphasizes changes in pain behaviour through education and training in relaxation strategies, problem-solving techniques, assertiveness training, cognitive restructuring and change reinforced patterns of pain behaviour. The behavioural and social learning theory addresses the notion that pain behaviours develop and persist as a result of learning. To change existing learning patterns of pain behaviour, the program considers operant (positive reinforcement of healthy behaviour and extinction of pain behaviour) and respondent techniques (relaxation techniques). Modeling is discussed in the parents' meetings to make parents aware of the influence of this mechanism on their child's pain behaviour.
The cognitive theory is concerned with attention towards pain and the effect of assumptions and beliefs about pain on an individual's pain coping strategies. Cognitive methods in our pain management program include psycho-education, rational-emotive therapy, distraction and thoughtstopping.

\subsubsection{Program content: adolescents}

Table 1 presents an outline of the training program as outlined above. Each week of the program addresses a specific theme. Theoretical aspects of these themes are introduced in the meetings and further developed during the self-management weeks. The written material provides additional information on the themes. Thereafter, each theme is followed by new exercises and homework assignments related to the theory already discussed. For example: adolescents were asked to practice the abdominal respiration or to complete the A-B-C scheme at home. With this scheme they learned to structure and evaluate their thoughts. The A represents a difficult situation they do not look forward to; B concerns a literal thought they have in relation to this event and its evaluation (positive or negative thought); and $\mathrm{C}$ the alternative positive and rational thoughts they can formulate to replace the negative thought. Adolescents were phoned every two weeks (during self-management weeks), for feedback and to motivate them. Phone contacts were based on therapist guidelines with regard to the content the written material in the self-management weeks, possible questions raised by adolescents and answering instructions. If the physical activity level was decreased because of the pain, adolescents choose an individual goal (gradually rebuilding a physical activity) based on pain-specific disability. With those who formulated an individual goal, progress or regressions in rebuilding the physical activity is discussed in the telephone contacts. Adolescents were invited to bring a peer to the group meeting in week 5. During this meeting the adolescents and their peers participate in a relay race called 'Pain is a millstone round your neck'. In this race the peers experience what it is like to do daily activities with a handicap. The relay race consists of multiple activities that the adolescents (divided in two teams) have to complete (for instance calculating, bouncing balls or running). The first team that crosses the finish line wins. The nuisance they experience during the relay race was chosen to be comparable as much as possible to the nuisance the participants experience due to chronic pain. Handicaps assigned to the adolescents varied from wearing a cassette recorder with loud music, an arm tied up behind one's back to wearing a water balloon on one's ankle. Evaluating the relay race gave the opportunity to discuss and compare the reactions peers displayed when their friend was in pain. Stimulating healthy behaviour (e.g. verbal praises for attending at school) was discussed with the peers. 
Table 1

Overview of the content of the cognitive-behavioural program during the 9-week training

\begin{tabular}{ll}
\hline Week 1 & Adolescents \\
\hline & Meeting \\
& Introduction and rationale for pain management \\
procedures and pain coping \\
Explanation of how pain works \\
Relaxation techniques; abdominal respiration \\
Physiology of mind-body connections
\end{tabular}

Week 2

Telephone contact-self-management

Relaxation; practicing abdominal respiration

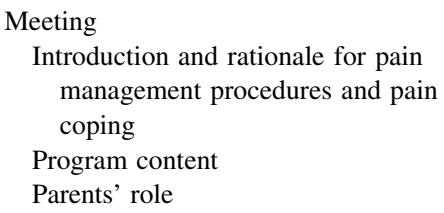

Week 3

Pain and stress

Cognitive restructuring

Parents

Meeting

Physical activity level

Watch over your own border

Progressive relaxation

Recognizing negative pain thoughts and replace

them with positive and rational thoughts

Week 4

Telephone contact-self-management

Living with pain: making plans

Attention and distraction

Progressive relaxation and physical exercise

Week 5

Meeting (with peers)

How does pain work?

Sharing your pain

Pain is a milestone round your neck-a relay race

Week 6

Telephone contact-self-management

Positive thinking

Progressive relaxation

Error of reasoning and rational thoughts

Week 7

Meeting

Assertiveness training

Relaxation through guided fantasy

Week 8

Telephone contact-self-management The environment; others in pain?

Fear of failure

Week 9

Meeting

Relapse prevention training

Relaxation through guided fantasy

Meeting

How to proceed in the future

Evaluation of the program

\subsubsection{Program content: parents}

In the first meeting the rationale for pain management procedures and pain coping are explained and the content of the program is presented (see Table 1). Parents are asked to apply the pain model of Loeser [19] to the pain of their child. In this model, pain is not solely considered as sensorial, but also as an emotional experience. The model was used as a starting point to discuss the impact of having a child with chronic pain in the family. General guidelines (based on Allen and Shriver [17]) to deal with pain (behaviour) are offered to the parents. For instance, the parents are advised both to take the pain of their child seriously-even when they doubt the seriousness of the pain and reward healthy behaviour. Parents were instructed to give positive verbal reinforcement if their child for instance participated in normal activities or attend at school. In the second parents' meeting (in the 9th week) perceived changes in the child's pain behaviour during the training are discussed. Attention is given to the way parents deal with the pain of their child. The influence of parental pain behaviour on the adolescents' pain behaviour is elucidated and discussed to make parents aware of modeling and its influence. The parents' own pain complaints and the way they cope with them are also discussed and compared with the coping strategies of their children. The second parents' meeting also contained an evaluation of the program. 


\subsection{Questionnaires}

\subsubsection{Feasibility}

To evaluate the feasibility of the program an evaluation form was developed for the adolescents and for their parents. These forms were administered at the end of the last meeting for the adolescents and in the last meeting for the parents. It consists of open-ended questions on how the adolescents and their parents experienced the training program: e.g. which aspects they valued most, what were the shortcomings, and how the program could be improved. The items on practical issues (e.g. concerning the timing and location of the meetings) give an indication about the applicability of the program in daily life.

\subsubsection{Pain and demographics}

The Pain Questionnaire [1] collected data at pretreatment $\left(T_{0}\right)$, post-treatment $\left(T_{1}\right)$ and follow-up $\left(T_{2}\right)$ on the adolescent's date of birth, gender, nationality, educational level and school year, as well as data on the localisation, frequency, duration and intensity of the pain.

\subsubsection{Pain diary}

Adolescents were asked to register their pain intensity during 2 successive weeks at pre-treatment $\left(T_{0} ; 2\right.$ weeks prior to the intervention), post-treatment $\left(T_{1}\right.$; directly after ending the intervention) and follow-up ( $T_{2} ; 6$ months after ending the intervention). Pain intensity was recorded three times daily, at breakfast, dinnertime and bedtime using a VAS with the anchors 'no pain' and 'the worst pain you can imagine'. The adolescents were asked to mark a position on the VAS that best matched their pain at that moment. The VAS is a valid measure for the assessment of self-reported pain intensity in chronic pain patients [20].

\subsubsection{Quality of life}

Because we were mainly interested in whether the training reduced the impact of pain on daily life and leisure activities, we measured the quality of life in terms of Functional Status as addressed on the Quality of Life questionnaire for Adolescents with Chronic Pain (QLA-CP) [21]. This is a shortened version of the Quality of Life Headache-Youth (QLH-Y) from Langeveld et al. [22]. The QLA-CP is reported to be reliable, valid and has suitable internal consistency and construct validity against COOP/ WONCA charts [21]. In the present study we administered the Functional Status at pre-treatment $\left(T_{0}\right)$, post-treatment $\left(T_{1}\right)$ and follow-up $\left(T_{2}\right)$ with a higher score (ranging from 0 to 3 ) presenting a better quality of life.

\subsection{Data analysis}

The feasibility of the program was tested by categorizing relevant items of the evaluation of both adolescents and their parents. Pain intensity scores were calculated by summing all pain intensity scores (from 0 to 100) in the pain diary and dividing them by the number of recording times (2 weeks $\times 3$ times daily $=42$ ). Scores of adolescents who completed only 1 week of the pain diary were multiplied by two; this was the case for one of the adolescents. A reduction in pain of at least $50 \%$ was considered as a clinically significant effect. A decrease in pain of more than $50 \%$ was considered to be a large reduction, and a decrease from 20 to $50 \%$ a moderate reduction. Mean scores were calculated for the outcome variable quality of life in terms of Functional Status. All adolescents who completed the questionnaires on at least two of the three data collection points were included in the analysis.

\section{Results}

\subsection{Subjects}

Of the 86 eligible adolescents, we randomly selected 8 adolescents. If a selected adolescent refused participation we randomly selected another adolescent. Finally, 21 adolescents (17 girls and 4 boys) with chronic pain had been randomly selected to obtain a pilot sample of eight participants. Of these 21 adolescents, 12 adolescents decided not to participate because their pain was no longer severe enough or because the pain had already disappeared. One of the adolescents requested to participate in a future group due to lack of time during the current study period. Besides the differences in gender (all selected boys decided not to participate), no differences were found in pain parameters between the 12 non-participants and the 8 participants. Table 2 gives the characteristics of the 8 adolescents participating in the program at baseline. During the first meeting it became clear that three girls knew each other from the same school.

\subsection{Feasibility}

\subsubsection{Participation}

Of the eight adolescent girls, one missed a meeting due to illness and another due to school examinations; the remaining six girls attended all meetings. The participants were cooperative, showed respect for each other, and over time became a cohesive and trustworthy group, allowing frankness during the discussions about their pain and daily lives. The variation in age and education level caused some delays due to the need to clarify some theoretical aspects of the program. During the telephone contacts in the selfmanagement weeks, we noticed that some adolescents had not read the information and/or completed the assignments, and some were difficult to reach at the arranged contact times. Four adolescents reported a reduction in their physical activity level because of their pain. These adolescents did not participate in any type of sport anymore. They were assisted in rebuilding their physical activity level. All four adolescents were active in sports again at the end of the 
Table 2

Characteristics of the study group $(n=8)$ at baseline

\begin{tabular}{|c|c|c|c|c|c|c|}
\hline Participant & Age (years) & Education level $^{\mathrm{a}}$ & Pain location & Frequency & $\begin{array}{l}\text { Duration of } \\
\text { pain (months) }\end{array}$ & $\begin{array}{l}\text { Pain } \\
\text { intensity }\end{array}$ \\
\hline 1 & 14 & Middle secondary school & Limb pain & At least 2 times a week & 30 & 38 \\
\hline 2 & 14 & Lower vocational training & Limb pain & At least 2 times a week & 8 & 32 \\
\hline 3 & 16 & Middle secondary school & Headache & Every day & 40 & 33 \\
\hline 4 & 16 & Higher secondary school & Abdominal pain & Every day & 96 & 66 \\
\hline 5 & 16 & Middle secondary school & Headache & At least 2 times a week & 84 & 55 \\
\hline 6 & 16 & Lower vocational training & Abdominal pain & At least 2 times a week & 3 & 66 \\
\hline 7 & 17 & Middle secondary school & Headache & At least 2 times a week & - & - \\
\hline 8 & 18 & Higher secondary school & Limb pain & Once a week & 36 & 77 \\
\hline
\end{tabular}

${ }^{a}$ Education levels were categorised into four groups: (1) lower vocational training; (2) lower secondary school, which is a four-year program; (3) middle secondary school, which is a five-year program and allows students to attend professional training; (4) higher secondary school, a six-year program and a prerequisite for university entrance.

b Measured with a visual analogue scale; scores ranged from 0 (no pain) to 100 (worst pain you can imagine).

program. Two of them started swimming, while the other two joint a fitness centre.

Two adolescents did not bring a peer to the meeting in week 5; one because the peer could not meet the time schedule and another because she wanted to avoid telling her participation in the training.

\subsubsection{Response rate of the evaluation study}

Of the 8 participants, 7 girls completed the questionnaires and 6 the pain diary at pre-treatment $\left(T_{0}\right) ; 5$ girls completed the questionnaires and 4 the pain diary at post-treatment $\left(T_{1}\right)$; and 5 girls completed both the questionnaires and the pain diary at follow-up $\left(T_{2}\right)$. Several contacts (by mail and telephone) were needed to gather the data. Of the 8 participants, 7 girls and the parents of five girls completed the evaluation form. These 6 parents (both parents of one girl were present) attended both of the parents meetings. The parents of one girl were present in the first, but not in the last meeting. One mother was unable to come because of young children at home, and another mother did not want to be involved in the intervention. Her daughter did not complete the questionnaires, diary or evaluation form, and both during and after the intervention the girl gave several reasons for her lack of compliance.

\subsubsection{Evaluation by the adolescents}

Most reactions about the program were positive: the adolescents valued being in a group with others. They reported that the program taught them how to influence their own pain and most experienced a change in their attitude towards pain and their life in general. Overall, they reported to practice the exercises about 4 days a week for 10-15 min a day. They found the assignments useful, even though they sometimes forgot to do them or lacked time to do them thoroughly. The theoretical aspects of pain and selfmanagement coping were reported to be easy to understand. All adolescents said they would recommend the training to others with pain.

The adolescents valued the participation of their parents and a peer. One girl was originally reluctant to bring a peer to the program (fearing her reaction), but afterwards reported that they both had enjoyed it. Suggestions to improve the training included more practice during the meetings (e.g. relaxation) and preferably groups with boys and girls.

\subsection{Evaluation by the parents}

As expected (because of their age), the girls did not tell their parents much about the program. Consequently, all parents found that the information given during the parents' meetings was useful and helped them to support their child in the training. All parents said that their child valued the training; one parent thought that the training was sometimes difficult because of the additional assignments and registrations. The girls did not ask their parents for help at any time during the training, and most parents were unaware of when their child was practicing at home. Parents valued the contact with other parents and found their exchange on how to deal with pain in the family as instructive and supportive. Additionally, the guidelines were considered useful in practice. Most parents changed their attitude towards their child when in pain and felt that they were more consistent in their behaviour.

Suggestions to improve the training were mainly practical, e.g. to start the adolescents' meetings at a later time, and to increase the number of participating parents to increase the exchange of experiences. One parent recommended more individual guidance of parents and/or children if required.

\subsection{The trainer's perspective}

The pilot study was conducted by a child psychologist and a graduate student in clinical psychology to allow a more individual approach when necessary (e.g. when additional explanation of the theory was needed). The allocation of tasks required both observation and guidance of the adolescents. The trainers exchanged experiences after the meetings and possible changes in approach were discussed. Because the trainers complemented each other they 
Pain intensity

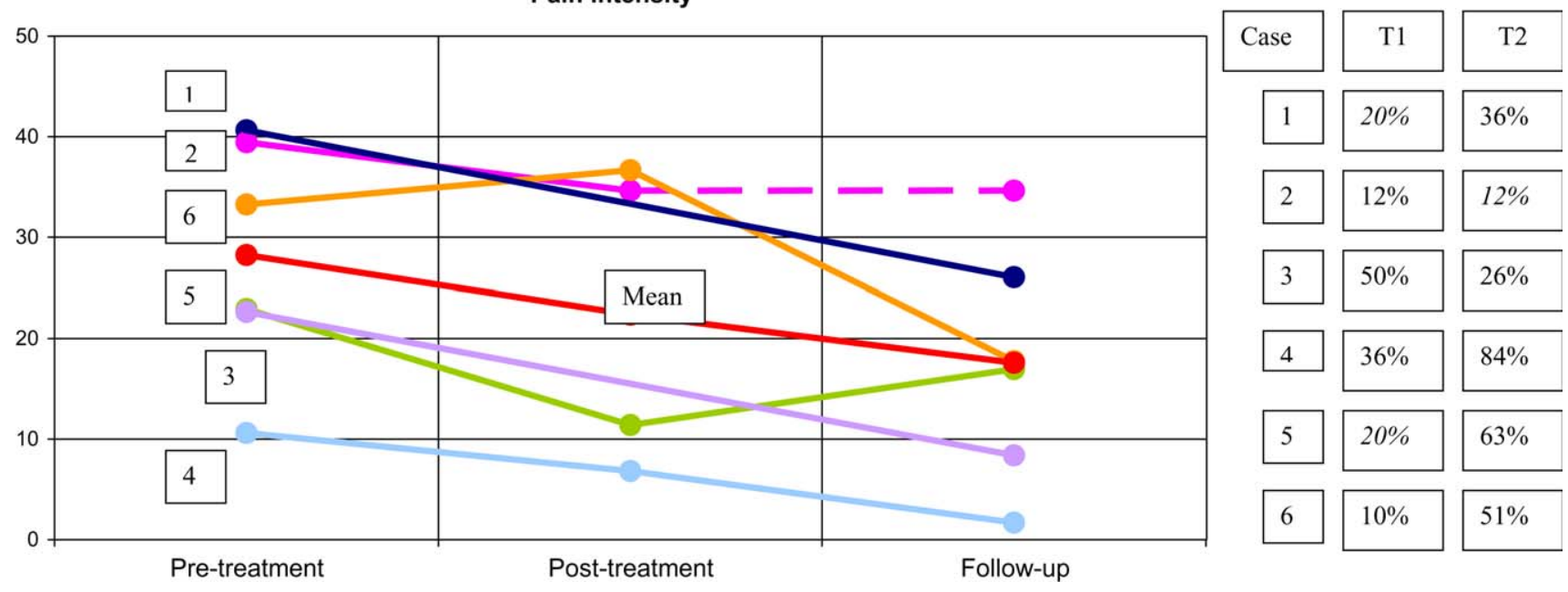

Fig. 2. Prospective absolute pain intensity scores of the adolescents on pre-treatment, post-treatment and follow-up. Change in percentage (pre-post and prefollow-up) is shown at right from the lines.

considered their cooperation to be valuable and essential in getting a more complete picture of each participant.

The trainers found that the first meeting had insufficient detailed information because most adolescents already knew how pain works (physical aspects). Not all adolescents completed their home assignments, and too much theory after school could be demotivating. In contrast, sufficient time to discuss their pain and its influence on their daily life seemed very important for the girls.

Preparations for the training, especially the preparatory talks in which individual tasks were allocated and materials were prepared for each meeting, were time consuming (about $2 \mathrm{~h}$ for each meeting), whereas the preparations for the telephone contacts took only about $10 \mathrm{~min}$ for each adolescent and the telephone discussion itself lasted about $15 \mathrm{~min}$ per child. Other preparations included arranging a suitable room for the sessions (including a gymnasium or suitable field for the relay race in week 5), and some refreshments during the training.

\subsection{Impressions on the effect of the program: pain and quality of life}

Based on our model, pain and quality of life were chosen as variables to assess therapy outcome. Fig. 2 shows the changes in pain intensity at post-treatment and follow-up compared to pre-treatment. At post-treatment $\left(T_{1}\right)$ two of the six girls showed no changes compared to pre-treatment, whereas four girls achieved a moderate to large decrease in pain intensity which was maintained during the follow-up period $\left(T_{2}\right)$. Three adolescents showed a clinically significant decrease $(>50 \%)$ in pain at $T_{2}$.

Fig. 3 shows the changes in quality of life. Overall, we found either no changes, small deteriorations or improve-
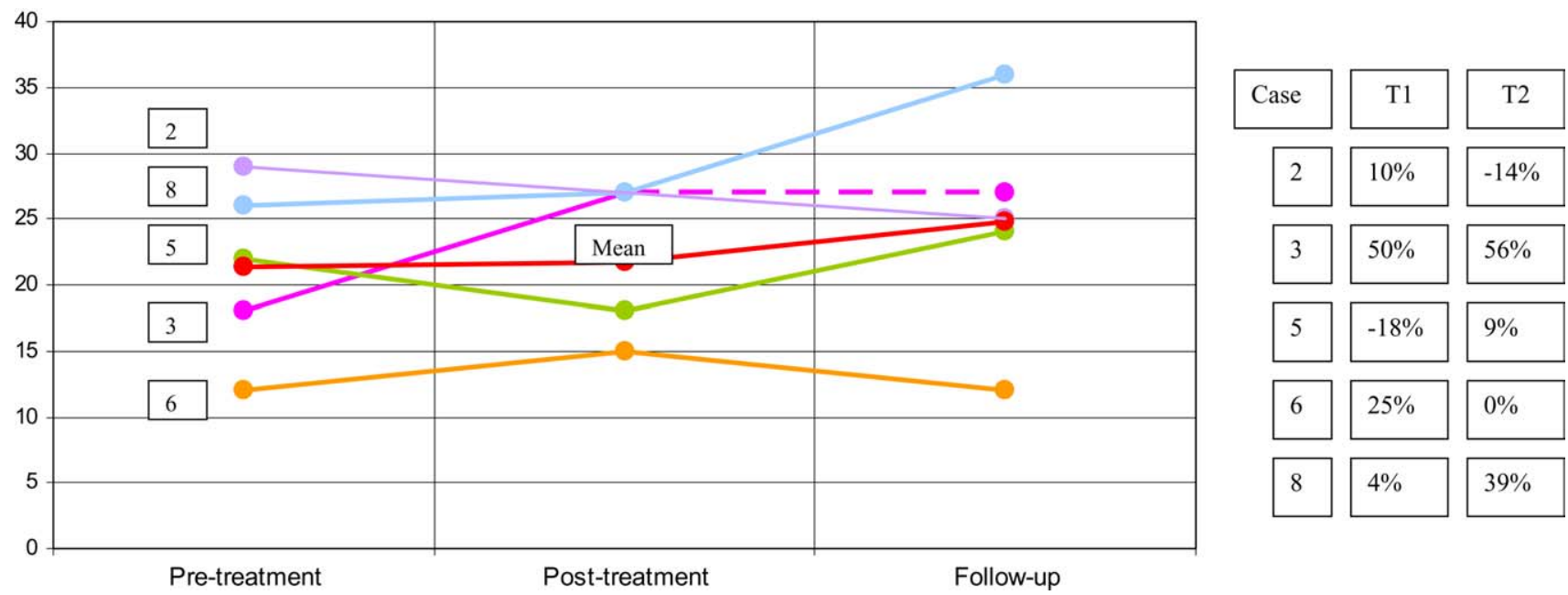

Fig. 3. Quality of life (functional status) scores of the 5 adolescents at pre-treatment, post-treatment and follow-up. Change in percentage (pre-post and prefollow-up) is shown at right from the lines. 
ments in the Functional Status of the group. The improvements ranged from moderate to large at both post-treatment $\left(T_{1}\right)$ and follow-up $\left(T_{2}\right)$.

\section{Discussion and conclusion}

\subsection{Discussion}

The present study provides evidence for the feasibility of a cognitive-behavioural program for adolescents with chronic pain. Both adolescents and their parents were positive about the content of the program. The adolescents reported that the training helped them to gain more control over their pain, and to feel less like a victim of pain. Parents evaluated the training and their involvement as supportive and informative because this enabled them to support their child in mastering their pain.

The compliance level in attending the meetings indicates that it is feasible to start immediately after school and finish before other activities (e.g. sport) begin. Although the compliance with and participation in the meetings was high, during the self-management weeks the assignments were not always completed. The adolescents might be better motivated if, in future, the assignments are started during the self-management weeks and then evaluated at the start of the following group meeting. In addition, emphasizing selfresponsibility may increase the return of questionnaires and pain diary after the training. A non-optimal response rate could be due to a perceived reduction of the usefulness and self-interest of completing the questionnaire after the training. It should be stressed, therefore, that the followups are part of the training and enable to determine the course of their pain.

In this pilot study the participants varied in age and educational level. Although they remained respectful towards each other, a more homogenous group is preferable and might enhance the sharing of experiences. The fact that three of the eight girls were from the same school had a positive effect on this group. However, trainers should be aware that this could also have some negative effects (e.g. gossip) and take appropriate action when necessary.

Regarding the second aim of this pilot study, the training showed an effect on pain and quality of life in the expected direction. Adolescents reported a lower level of pain intensity at post-treatment, which continued during follow-up. At the final data collection point three adolescents $(50 \%)$ had achieved a clinically significant reduction in pain, and the remainder showed a moderate change. Assuming that all those lost to follow-up would still report pain as severe as at pre-treatment, the adjusted proportion of adolescents that reached a reduction of at least $50 \%$ would be $38 \%$ (three out of all eight participants). Considering the subjective nature of pain, self-report measures on pain are the most valid and reliable method of assessment. Research has demonstrated that prospective diaries, as compared to retrospective questionnaires increase the validity of adolescents' pain report. Unlike retrospective methods, prospective diaries do not require children to summarize or average their pain and can elicit more accurate descriptions. The adolescents included in our study reported a mean retrospective pain intensity of $52 \mathrm{~mm}$ on a VAS in the questionnaire, though the mean pre-treatment prospective pain intensity was considerably lower, namely $28 \mathrm{~mm}$ (range $12-42 \mathrm{~mm}$ ) in the pain diary, meaning mild pain. The pain intensity (prospectively measured) at pre-treatment was relatively low in comparison with adolescents that were included in other clinically-based [23] or general population [24] studies. It may therefore be more difficult to demonstrate an intervention effect, because the pain reduction is expected to be larger in adolescents with higher pre-treatment prospective pain intensity scores. Nevertheless, the reductions in pain reported after our program is in line with other studies on the effectiveness of cognitive-behavioural treatment for children and adolescents with chronic pain $[6,11,16,17,24-26]$. However, the design of our pilot study does not allow us to conclude that the reductions in pain are only a result of our program. For example, Perquin and colleagues found that $51 \%$ of the children and adolescents with chronic pain at pre-treatment assessment show spontaneous remissions at 1-year followup [27].

In line with other studies showing that pain is negatively related to quality of life in adolescents with chronic pain $[21,28]$, we found an improvement in quality of life (i.e. in functional status) as a consequence of the decrease in pain intensity. In contrast with Bandell-Hoekstra [24] we found that the impact of pain on daily and leisure activities (Functional Status) was reduced after training.

The effectiveness of the program in this pilot study was based on the reduction in pain and improvement in quality of life. Following Turk et al. [29] other outcome domains can be included in future research. Beside pain relief and quality of life, outcomes concerned with a patients' actual physical function (e.g. time possible to walk, time from sit to stand per minute) [23] and emotional functioning, their disposition (e.g. adherence to treatment regimen, reasons for withdrawal) and satisfaction with treatment [29] or the adolescents' ability to relax could also be assessed.

\subsection{Conclusion}

The presented cognitive-behavioural program for adolescents with chronic pain is feasible in daily life of adolescents and their parents. The preliminary data showed effects in the expected direction namely a reduction of pain intensity and an improvement in quality of life of the adolescents after the intervention. As these successful results concern a small subgroup of the eligible participants, no definitive conclusions can be drawn. The need for a definitive study with a larger sample size and a randomized controlled design is highlighted by this pilot study. 


\subsection{Practice implications}

Our cognitive-behavioural training program appears to be suitable for a group of adolescents with chronic pain at different localisations. The program was considered to be feasible in daily life and theoretical aspects of pain and selfmanagement coping were reported to be easy to understand.

The trainers indicated that the techniques were easily applicable in the group meetings and telephone contacts with the adolescents. Though, the self-management weeks needs special attention, since some adolescents did not always complete the assignments during the self-management weeks.

The design of our program, group meetings alternated with self-management weeks, facilitates the applicability of the program and, at the same time gives adolescents the opportunity for modeling and relating to peers who share the same circumstances. In addition, the fact that this program is suitable for a wider spectrum of chronic pain sufferers enhances its utility in clinical practice.

\section{References}

[1] Perquin CW, Hazebroek-Kampschreur AAJM, Hunfeld JAM, Bohnen AM, van Suijlekom-Smit LWA, Passchier J, van der Wouden JC. Pain in children and adolescents: a common experience. Pain 2000;87: 51-8.

[2] Palermo TM. Impact of recurrent and chronic pain on child and family daily functioning: a critical review of the literature. J Dev Behav Pediatr 2000;21:56-69.

[3] Merlijn VPBM, Hunfeld JAM, van der Wouden JC, HazebroekKampschreur AAJM, Koes BW, Passchier J. Psychosocial factors associated with chronic pain in adolescents. Pain 2003;101:33-43.

[4] McGrath PA, Hillier LMHH, editors. The Child with Headache: Diagnosis and Treatment. Seattle, WA: IASP Press; 1999.

[5] Eccleston C, Morley S, Williams A, Yorke L, Mastroyannopoulou K. Systematic review of randomised controlled trials of psychological therapy for chronic pain in children and adolescents, with a subset meta-analysis of pain relief. Pain 2002;99:157-65.

[6] Sanders MR, Shepherd RW, Cleghorn G, Woolford H. The treatment of recurrent abdominal pain in children: a controlled comparison of cognitive-behavioural family intervention and standard pediatric care. J Consult Clin Psychol 1994;62:306-14.

[7] Lee BH, Scharff L, Sethna NF, McCarthy CF, Scott-Sutherland J, Shea AM, Sullivan P, Meier P, Zurakowski D, Masek BJ, Berde CB. Physical therapy and cognitive-behavioural treatment for complex regional pain syndromes. J Pediatr 2002;141:135-40.

[8] Elgar FJ, McGrath PJ. Self-administered psychosocial treatments for children and families. J Clin Psychol 2003;59:321-39.

[9] Larsson B, Daleflod B, Håkansson L, Melin L. Therapist-assisted versus self-help relaxation treatment of chronic headaches in adolescents: a school-based intervention. J Child Psychol Psychiatr 1987;28:127-36.

[10] McGrath PJ, Humphreys P, Keen D, Goodman JT, Lascelles MA, Cunningham SJ. The efficacy and efficiency of a self-administered treatment for adolescent migraine. Pain 1992;49:321-4.
[11] Griffiths JD, Martin PR. Clinical-versus home-based treatment formats for children with chronic headache. Br J Health Psychol 1996;1:151-66.

[12] Kroener-Herwig B, Denecke H. Cognitive-behavioural therapy of pediatric headache: are there differences in efficacy between a therapist-administered group training and a self-help format? J Psychosom Res 2002;53:1107-14.

[13] Gilbert MC. Developing a group program in a health care setting. In: Schopler JH., Galinksky MJ, editors. Groups in Health Care Settings. Binghamton, NY: Haworth Press; 1990. p. 27-44.

[14] Schaefer CE. Preface. In: Schaefer CE, editor. Short-term Psychotherapy Groups for Children: Adapting Group Processes for Specific Problems. Northvale, NJ: Jason Aronson; 1999. p. vii-xii.

[15] Martin PR, Soon K. The relationship between perceived stress, social support and chronic headaches. Headache 1993;33:307-14.

[16] Barry J, von Baeyer CL. Brief cognitive-behavioural group treatment for children's headache. Clin J Pain 1997;13:215-20

[17] Allen KD, Shriver MD. Role of the parent-mediated pain behaviour management strategies in biofeedback treatment of childhood migraine. Behav Ther 1998;29:477-90.

[18] Merlijn VPBM, Hunfeld JAM, van der Wouden JC, HazebroekKampschreur AAJM, Passchier J, Koes BW. Factors related to the quality of life in adolescents with chronic pain. Submitted for publication.

[19] Loeser JD. A definition of pain. Univ Washington Med 1980;7:3-4.

[20] Jensen MP, Karoly P, Braver S. The measurement of clinical pain intensity: a comparison of six methods. Pain 1986;27:117-26.

[21] Merlijn VPBM, Hunfeld JAM, van der Wouden JC, HazebroekKampschreur AAJM, Passchier J. A shortening of the QLH-Y: the quality of life questionnaire for adolescents with chronic pain (QLACP) and its psychometric qualities. Psychol Rep 2002;90:753-9.

[22] Langeveld JH, Koot HM, Loonen MCB, Hazebroek-Kampschreur AAJM, Passchier J. A quality of life instrument for adolescents with chronic headache. Cephalalgia 1996;16:183-96.

[23] Eccleston C, Malleson PN, Clinch J, Connell H, Sourbut C. Chronic pain in adolescents: evaluation of a programme of interdisciplinary cognitive behaviour therapy. Arch Dis Child 2003;88:881-5.

[24] Bandell-Hoekstra IE. Headache, coping and quality of life in children. $\mathrm{PhD}$ Thesis. Rosmalen: Maastricht University, The Netherlands, 2003.

[25] Larsson B, Melin L. Chronic headaches in adolescents: treatment in a school setting with relaxation training as compared with informationcontact and self-registration. Pain 1986;25:325-36.

[26] Osterhaus SO, Passchier J, van der Helm-Hylkema H, de Jong KT, Orlebeke JF, de Grauw AJ, Dekker PH. Effects of behavioural psychophysiological treatment on schoolchildren with migraine in a nonclinical setting: predictors and process variables. J Pediatr Psychol 1993; 18:697-715.

[27] Perquin CW, Hunfeld JAM, Hazebroek-Kampschreur AAJM, van Suijlekom-Smit LWA, Passchier J, Koes BW, van der Wouden JC. The natural course of chronic benign pain in childhood and adolescence: a two-year population-based follow-up study. Eur J Pain 2003;7:551-9.

[28] Hunfeld JAM. Passchier J, Perquin CW, Hazebroek-Kampschreur AAJM, van Suijlekom-Smit LWA, van der Wouden JC. Quality of life in adolescents with chronic pain in the head or at other locations. Cephalalgia 2001;21:201-6.

[29] Turk DC, Dworkin RH, Allen RR, Bellamy N, Brandenburg N, Carr DB, Cleeland C, Dionne R, Farrar JT, Galer BS, Hewitt DJ, Jadad AR, Katz NP, Kramer LD, Manning DC, McCormick CG, McDermott P, McGrath P, Quessy S, Rappaport BA, Robinson JP, Royal MA, Simon L, Stauffer JW, Stein W, Tollet J, Witter J. Core outcome domains for chronic pain clinical trials: IMMPACT recommendations. Pain 2003;106:337-45. 